not total deafness, the post-mortem examination showed intact tympanic membrane, no injury to stapes, or annulai ligament, or membrana secundaria; no haemorrhage into the labyrinth; blood clot in both middle ears; no fracture of the base. ${ }^{8}$

Various explanations of the causation of traumatic neurosis, based on pathological findings, have been offered. For instance, changes in the small cranial blood ressels, changes in the myeline sheaths, small haemorrhages, air cmboli following decompression as a result of high explosives, etc.; finally, as morbid anatomy throws so little light on the subject, it is suggested that we have here molecular changes in the nerve and nerve cell." It will be a great injustice to the thousands who suffer from this malady, as well as a great loss to science, if something be not attempted at this time to enlighten us on the pathological changes present. Rational treatment demands information; and rational treatmont, not haphazard empiricism, ought to be given to those suffering from these distressing symptoms.

\section{Basis of Treatment.}

The treatment is founded on the following anatomical and physiological basis:

1. At the synapses there is structural discontinuity of the nerves.

2. The results produced by impulses travelling in a nerve depend on the way the fibre ends and not on any difference in the impulses themselves. "Impulses pro. duced in the optic nerve by light are identical with those produced in the auditory nerve by sound." "The difference recognized by the organism must be due to analysers in the central nerrous system."

3. At the synapses different physiological systems come into touch with each other, and so co-ordinate action in diverse systems is possible.

4. At the synapses there is always a spread of the nerve impulse, and the greater the impulse the greater the spread.

With this basis we are working in the following hypoth sis:

As a result of the high explosive with enormous and sudden increase of pressure in the ear, there occars a dissolution of the permanent auditory pathway, and a spread of the nerve impulse into other adjacent paths. The auditory stimulus no longer reaches its goal and deafness results. Such a dissolution may occur at one or at all the synapses. It may not be complete, and a maximal stimulus may be still able to get through.

To re-establish connexion two things have to be clonc: (1) 'lo connect up the permanent part, and (2) to stop dissipation; but dissipation is like a bad habit, the longer it has been going on the worse it is to break.

To help, we have the fact that habit and association of activity facilitate transmission of impulses. Nerve im. pulses tend to pass over an accustomed and long-established path, so the most favourable cases are those in which com. plete dissolution has not occurred. The must unfavourable are those where there has been complete dissolution and total deafness to tuning-fork, voice, and noise, no matter the intensity or pitch. It may be that this dissipation of the nerve impulses will help to account for the associated nervous phenomena.

\section{Treatment.}

In the totally deaf, either in the one or both car's, the method pursued is briefly as follows:

1. Tuning-forks are applied: (a) To the bone (for example, mastoid); or (b) through resonators, attached to the ear by tube; $(c)$ through the air. In our worst cases the time given to $(a),(b)$, or $(c)$ varies with the amount of deafness.

2. The voice is used: (a) Through resonators with tube in ear: (b) through speaking tubes; $(c)$ without any aid.

3. Each period of treatment is very short, for fatigue is rapidly produced. Thus we may have headaches, vertigo, sweatings, etc., and occasionally pain is complained of, if the treatment be too long.

4. As soon as possible carefully graduated physical exer. cises are given. In exercise the two cssentials are short duration and no bending. The treatment (except the drill) is giren twice a day in the worst cases; it onght to be giren twice in all.. In the worst cases, when it is diffi. cult to pass from bone to resonator, we use the piano. Tre iind that at each acessire stage we have to use summa. tion of stimuli; thus, not only must the fork on the resonator be lept up for some time, but with the voice we liare to repeat the word, but even then there is a marked delay before the response comes. In the later stages tho delay is still present. There it appears to be not so mucl that he does not hear, but that lie hesitates to attach the word to the sound, for, if asked what he thinks it is, he frequently answers correctly.

5. As early as possible we ascertain if the semicirculat canals are acting, because when there is reaction to tho caloric or rotation tests in totally deaf cases we feel justitied in continuing treatment for some time.

\section{Sumary.}

1. The normal stimulus (musical notes or voice) is an aclequate stimulus for the nerve and is the best stimulus. Electricity is contraindicated and likely to do harm siuce it so easily produces vertigo.

2. In the totally deaf, bone conduction is perceived before air conduction. It is essential to differentiate vibrations from musical notes.

3. In these cases summation of stimuli plays an important part in the perception of sound.

4. There is a marked diminution of the duration of hearing along the whole series of forks, both through bone and air. This corresponds and exists pari passu witl concentric limitation of the fields of vision. Often both improve together. Frequently the field of vision is more retracted on the side having the greater deficiency of hearing.

5. If the conducting mechanism is damaged or destroyed it not only takes longer to get improvement but completo recovery cannot be expected.

6. Prognosis is good as a rule, especially in cases whero there is no trauma demonstrable in the peripheral organ, no history of aural vertigo, and a normal caloric reaction. The most noteworthy exception met with so far is damage to the serenth nerve. In these cases hearing returns but slowly, and, so far as we have observed, not perfectly, even with a normal drum membrane, little if any signs of middle-ear inflammation, and a caloric reaction present.

7. As a result of the concussion due to high explosives there is frequently a trauma demonstrable in the ear. This may be accompanied by neurosis (traumatic neurosis), especially headaches and vertig). The perception of sound is diminished over the whole normal range; the diminntion may be so great as to totally abolish perception of sound. I liare not seen a case yet associated with tone islands. What $I$ do find is a diminution all along the scale both for bone and air condaction.

8. As the deafness diminishes there may persist for a long time an inability to grasp intelligently what is said or to retain the memory of it. Thus a word may have to be repeated two or three times before the patient gets it; or, if he be asked to repeat tivo or three numbers given con. secutively, he will repr at the last one; lie knows that there were others but did not get them.

REFERENCES.

1 Mott, Lettsomian Lectures, Trans. Roy. Soc. Med, 1916, vol. xxxix p. 172. Wejerine, Sémiologie des affections du système nerveux. Yaris, 1914, 1. 1123.' 3 Proc. Roy. Soc. Med.. Otological Section, Mfarch, 1916, p. 29. "4ee Mott, loc. cit. "Bayiliss, Principles of General Physiology, pr. 387, 512,513.

\section{RESLLTS OF SCOPOLAMINE-MORPHINE TREATMENT DURING LABOUR IN 150 CONSECU'IITE CASES.} Ir:

\section{W. OSBORNE GREENWOOD, M.B., B.S.LOND.}

THF majority of the cases in the present series were conducted at a prirate maternity nursing home; the remainder at the patients' own homes. I hare no experience of this treatment in hospital wards where other patients were present. But from the observations of others it rould appear that the results obtained in such wards are not the best; there would seem to be no added rislss to mother or infant, but the condition aimed at, namely, complete amnesia, is not attained nearly so often. Thus, Gauss's percentage of complete amnesia is 86 , a great many of the cases haring been treated in hospital mards. Sir J. Halliclay Croom tells me that his hospital cases are not 
infrequently failures, but that he never has a failure in private cases.

Of the present series only two cases failed to respond and sliowed no amnesia. These were patients at their own homes in cottages, were both multiparae, were first seen when the external os was fully dilated, the subsequent course of labour was relatively rapid, and the value of suitable environment was not appreciated or could not be obtained. Five other cases remember the final passing of the head over the perineum or the expulsion of the placenta, but affirm that it was only a knowledge of something occurring during parturition and was not a recollection of "pain." This gives 98.66 per cent. of successful case's of amnesia, and the results in this respect coincide very closely with those of Sir Halliday Croom. For the attaimment of these results $I$ am convinced that not only is a nursing home necessary, but a thoroughly trained and competent staff is no less essential.

Another vital necessity is the constant attendance of the accoucheur, not only that neither mother nor infant runs any risk, but because the response by different patients is so variable. It has been my experience that while some patients may be kept in an ideal condition of amnesia by a repetition of the scopolamine in from two to three hours or even longer, others will need the same dosage every hour or hour and a half. In a general way a rapid labour needs a more frequent dosage, but this is by no means invariably the case. Elements of failure are introduced unless the accoucheur is present from the first dose to the completion of labour. A routine dosage cannot be estab. lished. Constant exercise of the accoucheur's judgement as to repetition of scopolamine is of paramount importance.

The time required to induce amnesia is very variable. In one case it was complete in twenty minutes, and in five others it was induced in half an hour. On the other hand, I have had two cases in which amnesia was not attained until four how s after the first injection.

of the 150 cases, 106 were primiparae and 44 were multiparae, that is, 70.66 were primiparae. The ages of the priniparae ranged from 17 to 49 . The multiparae included two with their ninth child. Of these cases four were breech presentat.ons, two were transverse presentations; one was almost a typical brow presentation, the actual presenting part being about an inch posterior to the brow; the remaining cases were vertex, in only two of which was the occiput posterior. In three of the mother's there were mitral lesions; in three there was very marked albuninuria-one was in $\mathrm{my}$ own practice, the two others were sent to me by other medical men. One of these was a patient aged 49 year's. Oedema was general and pronounced, and the patient was therefore kept in bed on arrival until labour began. I saw her at 3 a.m., and gave her the first injection (scopolamine and morphine) at 3.20 a.m. The os uteri was then the size of a shilling. At 8 a.m. the os was fully dilated, and at 9.30 a.m. a living female child was born with no signs whatever of oligopnoea; there was not the slightest hesitation in breathing though the umbilical cord was twice round the neck. The perineum was very oedematous, and ruptured severely almost on the first pressure of the head. It was sutured, and healed by first intention. The child weighed over $8 \mathrm{lb}$., and is now 4 months old and well. The other two cases with marked albuminuria also had oedema; each had a living child, one being now 6 months old, the other 16 montlis.

There were three cases of post-partum haemorrhage; all were multiparae, and all had had severe post-partum haemorrhage before (one of them with the last two children). It would seem, therefore, to be unjust to attribute the haemorrhage in these cases to the drugs. In all the haemorrhage was quickly controlled by manipu. lation and the use of pituitrin. One other case had had haemorrhage with a previous child, but although it was certainly in excess of normal during this last parturition it never became really serious. One of the cases had the rare condition of premature detachment of the placenta, and this was responsible for one of the infant mortalities. The placenta could not be felt on vaginal examination, although it possibly encroached on the danger zone.

In the present series of cases there has been no maternal death; of the infants three have died (all stillborn). I may incidentally remark that there has been no infant fatality in $\mathrm{my}$ cases since the completion of the 150 cases. This gives an infant mortality of 2 per cent., as against the usual average of 2.25 to 2.5 per cent. in general midwifery practice. Even if these fatalities were due to scopolamine. morphine, neither the maternal nor the infant mortality is as high as the general average. The three deaths were as follows:

1. The case of premature detachment of the placenta mentioned above.

2. A breech presentation which was originally transverse and was turned; the head and both arms were extended, and it was impossible to reach them. 3. A difficult forceps extraction with cerebral or medullary
haemorrhage.

As far as I can judge, scopolamine-morphine had not the slightest influence on these three fatalities.

It may be interesting to mention here three other cases of more than ordinary difficulty:

1. The second transverse presentation referred to above occurred in a patient with a flattened pelvis. When the first injection was given the os was three-fourths dilated. Chloroform was also immediately administered, and by combined internal and external version the child was turned to a vertex presentation and the membranes ruptured. Chloroform was then stopped and the injections proceeded with; eight were given altogether in fifteen and a half hours. Uterine contractions remained vigorous the whole time, but, as at the end of fourteen and three quarter hours the head had not yet fully engaged the pelvic brim, I decided on the high forceps operaengaged the pelvic brim, I decided on the high forceps opera-
tion. The child was extracted with difficulty. It was very tion. The child was extracted with difficulty. It
vigorous and showed no signs whatever of oligopnoea.

vigorous and showed no signs whatever of oligopnoea.
2 . A case of flattened pelvis and a beaked symphysis pubis, 2. A case of flattened pelvis and a beaked symphysis pubis,
the beak projecting backwards. The child was extracted with forceps after an anxious consideration as to whether Caesarean section might not be necessary. The head was kept to the left as much as possible and the perineum incised to the left of the median raphe. The patient had been under treatment ten hours, and the child was born living and well.

3. A small round pelvis with a R.O.P. presentation. The patient was under scopolamine-morphine eighteen hours. The occiput was rotated forwards, but tended to return until it was finally rotated forwards at the vulva and passed under the symweighed $8 \frac{1}{2} \mathrm{lb}$., was quite healthy, and had no trace of oligopnoea.

Effects on the Child: Oligopnoea.

As, perhaps, no symptom has given rise to so much mis. giving as oligopnoea $I$ propose to set out $\mathrm{my}$ experience of it. If the treatment is administered as it should be (with the admittedly attendant watchfulness it demands) there is no need whatever for so deep a grade as to produce "blue babies." A slight degree of oligopnoea is certainly not uncommon, though its incidence diminishes with the increased experience of the operator. Marked and persistent-cyanosis points to an error of technique or of judgement.

The slight oligopnoea to which $I$ have referred is charac. terized by the following features: An initial cry at the moment of expulsion, immediately followed by a marked quictude which may persist even for an hour; if the re. spiration is altered at all it is a little slower and perhaps a little shallower; heart beats continue vigorous and normal in every respect; the child simply seems lazy or tired.

of the 150 cases under consideration, 23 (15.33 per cent.) showed this slight oligopnoea. But of these 23 cases, three had a second small dose (gr. $\frac{1}{1_{2}}$ ) of morphine-a practice I have long since abandoned. Omitting these three cases we get 13.33 per cent. of slight oligopnoea. Early in 1916 I used eutocine (the detoxicated morphine of Lauret) in four cases with very small doses of scopolamine; in each of these cases the infant was slightly oligopnoeic, and this certainly suggests more than a coincidence, especially as the only three cases where a second dose of morphine was given showed the same tendency. Of the above 23 cases, therefore, 16 were treated exactly as is my present procedure. This gives a slight oligopnoea in 10.66 per cent.

The average time the above 23 cases were under treatment was 6 hours 39 minutes; omitting the three cases in which morphine was given twice and the four cases in which eutocine was used, the remaining 16 were under treatment 4 hours 45 minutes. This, I am convinced, contains the whole philosophy of oligopnoea; if it is to bo avoided altogether, morphine should certainly not be given late in labour; or, if given, the morphine should be proportionately diminished in dose. The average length of time during which the cases in my series presenting no oligopnoea were under treatment was 7 hours 35 minutes. The cases in which the infants were at all oligopnoeic, it 
will be seen, were the cases of short duration. This clearly indicates that oligopnoea is due mainly, if not entirely, to the morphine. $1 \mathrm{am}$ not suggesting that this slight degree of oligopnoea is critical, for $I$ have intentionally refrained from interference, though prepared to resort to artificial respiration if necessary, but the condition of the infants was never alarming. Only in two cases have I resorted to artificial respiration-one a difficult forceps extraction, and the other a case in which the cord was three times round the neck of the infant. Both cases recovered.

\section{Effect on the Mother.}

I have made it a constant practice to begin this treatment early, uften as soon as labour had definitely begun. In a few of the cases there appeared to be slight retarda. tion of the uterine contractions after the initial dose, but after it only. My experience has been that after the second and subsequent doses the contractions have become normal, and in not a few cases - really severe. I feel justified in saying this has probably quickly regained the little time that may have been lost, and therefore labour on the whole has not been retarded. Possibly, in the few cases where an initial delay appeared to occur, there was present some slight idiosyncrasy to morphine.

Perhaps the most striking after-effect on the mother is the remarkable absence of exhaustion and shock. After a labour lasting twenty-four to forty-eight hours or more the patient will often sleep a few hours, and on awaking be astonished that labour is over, and have such a feeling of well-being that she cannot realize anything has occurred.

So long as complete amnesia, and not analgesia, is aimed at and maintained, $I$ have no hesitation in saying my experince proves that there is no risk either to mother or infant. If pushed to the slightly further stage of analgesia the risk may be grare; but as the margin between amnesia and analgesia is small, the necessity for constant watchfulness by the obstetrician is all the more emphasized.

The influence on the pulse is interesting. In $11_{3}^{2}$ per cent. of the above 150 cases the pulse-rate was in. creased; in 36 per cent. it remained the same; in the remaining $52_{3}^{2}$ per cent. it was diminished. In all the cases except two the character of the pulse was at least as good as at the onset of labour; usually it was improved. The two exceptions were cases complicated by influenza and an acute attack of cholelithiasis respectively.

While my next observation ma $r$ not be of any particular tochnical interest, it is certail $y$ of some moment from a national point of view at the , isent time. In this serics of 150 cases I have certain litowledge that in nine the parents.had resolutely refused to entertain the idea of a child. Hearing of the scopolamine-morphine treatment, they decided the time was ripe to embark upon the responsibilities of parentage. The result is an increase of 6 per cent. in the birth-rate in this series. This figure three times covers the infant mortality at birth in the 150 cases, and is rather significant.

\section{THE INTRAVENOUS INJECTION OF TISOL IN THE TREATMENT OF GENE: IL SEPSIS,}

As Illustrated BY Two Cases of Septic Otitid THROMBOSIS OF THE SIGMOID SINUs. EY

J. S. FRASER, M.B., F.R.C.S.E., ASBISTANT SERGEOY:

ANDREW CAMPBELL, M.B., AND E. D. D. DICKSON, CLINICAL AssistiNTs,

TAR AND THROAT DEPARTMEYT, ROTAL INITIIJART, EDINBCRGH.

(From the Ear and Throat Department, Roral Infirmary, Edinburgh, under the charge of A. Logan Turner, M.i., F.R.(.S.E., F.R. -.E.)

THE method of treating generalized sepsis by the injection of the blood with a solution of hypochlorous acid in the form of eusol was introduced by Lorrain Smith, Ritchie, and Rettie, who described the recovery under this form of treatment of a case of grare puerperal septicaemia. ${ }^{2}$ They pointed out that the most probable interpretation of the result was that the hypochlorous acid destroyed toxin circulating in the blood, and that there was no evidence that the eusol injected acted as a bactericide.

The following two cases illustrate the application of the method to the generalized sepsis which follows otitic thrombosis of the sigmoid sinus. They aro examples of somewhat different types of sepsis. In the first, after the operation there was, apart from a patch of pleurisy, no sign of the derelopment of secondary foci of infection. The symptoms of blood sepsis were, however, very marked, and the patient had passed into a desperate condition; the treatment by eusol injection was applied at this stage. In the second case a large focus of sepsis developed in the right ilium. The injection of eusol produced only tem. porary benefit. When this focus was drained, however, the patient recovered.

It may be concluded that the presence of a large septic focus is a condition which cannot be alleviated by intravenous injection of eusol. To neutralize toxin in the blood, even by repeated injections of eusol, is insufficient to control the toxaemia in such a condition, becauso the local focns still remains active, and continually adds new toxin to the circulation. The contrast between these cases furnishes a suggestion as to the type of septic infection in which ensol injection is of value.

\section{Case I.}

R. W., male, aged 6 rears, was first seen on October 8th, 1910 suffering from chronic discharge from the right ear. sufering from chronic discharge from the right ear. The right sent to the ward for adnission, but, as he cried, his mother refused to leare him. He was brought back six rears tater refused to leave him. He was brought back six years later (April 7th, 1916) complaining of pain in the right ear of three
weeks' duration. He had had a rigor wheu the pain began, and weeks' duration. He had had a rigor wheu the pain began, and
now suffered from pain in the neck, frontal headache, drovst. now suffered from pain in the neck, frontal headache, drowsi
ness, and mild delirium. There was no history of recent vomiting or giddiness.

On admission the temperature was $99^{\circ} \mathrm{F}$., the pulse 100 , and the respirations 24 . The boy looked foightened, restless, and kept his head flexed; the tongue was moist but slightly furred. There ras still a polrpus in the right meatus and tendernes. was present on pressure one inch behind the right mastoid.

Functional examination of the cochlear apparatus showed that the right ear was tion of the cochlear apparatus showe hat the right ear was guite deaf (complete deafness with the noise apparatus in the good ear). Examination of the vestibular abparatus shorred complete loss of reaction, bnt there was no an old destruction of the inner ear.

\section{First Operation.}

On the erening of admission the temperature rose to $102.4^{3}$ and on the following day the first operation was performed (J. S. F.). The mastoid cortex showed two large holes through which cholesteatoma protruded, but there was no subperiosteal abscess. In removing the mastoid cortex the sigmoid sinus, which was exposed in the posterior part of the greatly enlarged mastoid carity, was injured in the region of the upper knee and mastoid carity, was injured in the region of the upper lonee and
bled frecly. After controlling this haemorrhaje the radical operation was completed-the malleus and incus being absent. operation was completed-the malleus and incus being absent. It was now seen that the lateral semicircular canal had been opened by the cholesteatoma. Accordingly the labyrinth opera-
tion (Neumann) was performed. The sigmoid sinus ivas not tion (Neumann) was performed. The sigmoid sinus was not further investigated at this time. The operation cav
packed with iodoform worsted and the wound left open.

packed with iodoform worsted and the wound left open.
The boy hn: $t$ a good night; no rigor or vomiting. The hear on April $Q, i$ was still tucked forward. At 8 p.n. the temperat uic rose to $104.4^{\circ} \mathrm{F}$

On April loth blood was taken from an arm rein for culture. The report received later stated that a Gram-positive staphy. lococcus and a Gram-negative bacillus were present. On lumbar puncture the fluid spurted ont under great pressure, but was quite clear, and a report received later stated that there was no c...eess of cells and no organisms on culture.

\section{Second Operation.}

As the patient's general condition was unsatisfactory aud the temperature swinging, the lateral sinus was exposed in a back ward direction until healthy wall was reached. The jugnlar ward direction until healthy wall was reached. The jugthlar bulb end of the sinus was also further exposed. The anterior: wall was slit up and \& partly organized clot found. Free bleeding ras obtained from the upper end, which was occluded
by packing. Towards the bulb apparently healthy red clot way by packing

On April 11th lie felt better, and the temperature wa: 98", but next day it rose at $4 \mathrm{p} . \mathrm{m}$. to $103^{\circ}$, and at $81 \mathrm{l} . \mathrm{m}$. to $105 \mathrm{l}$.

\section{Third Operation.}

On $A$ pril 13th the right internal jugular vein was exposel and found to be clotted down to the juuction with the common facial. The rein was diviled between ligatures and the mper end opened and stitcheil to the skin. Both mostoid and ueck wonnds were left open. On April 15th his condition was fairl. satisfactory. The jugnlar bulb was washed through front satisfactory. The jug
mastoid wound to neck.

On April 18th and 19th the evening temperature was elerated, and on April 20th it reached $104 \%$. The wounds showed no 